2012-6

\title{
Fiber Optic Monitoring of Subsea Equipment
}

\author{
David Brower \\ Astro Technology \\ John Hedengren \\ Brigham Young University, john.hedengren@byu.edu
}

Cory Loegering

Alexis Brower

Astro Technology

Karl Witherow

See next page for additional authors

Follow this and additional works at: https://scholarsarchive.byu.edu/facpub

Part of the Chemical Engineering Commons

\section{Original Publication Citation}

Brower, David, et al. "Fiber optic monitoring of subsea equipment." ASME 2012 31st International Conference on Ocean, Offshore and Arctic Engineering. American Society of Mechanical Engineers, 2012.

\section{BYU ScholarsArchive Citation}

Brower, David; Hedengren, John; Loegering, Cory; Brower, Alexis; Witherow, Karl; and Winter, Karl, "Fiber Optic Monitoring of Subsea Equipment" (2012). Faculty Publications. 1716.

https://scholarsarchive.byu.edu/facpub/1716

This Peer-Reviewed Article is brought to you for free and open access by BYU ScholarsArchive. It has been accepted for inclusion in Faculty Publications by an authorized administrator of BYU ScholarsArchive. For more information, please contact ellen_amatangelo@byu.edu. 


\section{Authors}

David Brower, John Hedengren, Cory Loegering, Alexis Brower, Karl Witherow, and Karl Winter 


\section{Proceedings of The 31st International Conference on Ocean, Offshore and Arctic Engineering

\section{OMAE2012/84143}

\section{FIBER OPTIC MONITORING OF SUBSEA EQUIPMENT}

\section{David Brower*}

Astro Technology, Inc.

510 Ellington Field, Ste 200

11602 Aerospace Ave

Houston, Texas 77034-5507

Email: dbrower@astrotechnology.com

\section{Alexis Brower}

Astro Technology, Inc.

510 Ellington Field, Ste 200

11602 Aerospace Ave

Houston, Texas 77034-5507

Email: abrower@astrotechnology.com
John D. Hedengren

Department of Chemical Engineering 350 Clyde Building

Brigham Young University

Provo, Utah 84602

Email: john.hedengren@byu.edu

\section{Karl Witherow}

Ocean Flow International

2100 West Loop South

Suite 500

Houston, Texas 77027

Email: kwitherow@ocean-flow.com
Cory Loegering

Apache Deepwater LLC

2000 West Sam Houston Pkwy South

Suite 1600

Houston, Texas 77042-3622

Email: cory.loegering@apachecorp.com

\section{Karl Winter}

Ocean Flow International

2100 West Loop South

Suite 500

Houston, Texas 77027

Email: kwinter@ocean-flow.com

\section{ABSTRACT}

Bass Lite deepwater field in the Gulf of Mexico, at water depths of approximately 2,050 $\mathrm{m}$ (6,750 feet), commenced operation in February 2008. Natural gas is produced from Bass Lite via a 90-km (56-mile) subsea tieback to the Devils Tower Spar. This project involved several innovations, one of which was the incorporation of a fiber optic sensing system that measures realtime temperature, pressure and strain along the pipeline length. This is a first of its kind innovation that is in actual operation.

\section{NOMENCLATURE}

APC Advanced Process Control

$d_{\text {avg }} \quad$ Average pipeline diameter $(\mathrm{m})$

$d_{i n} \quad$ Inside pipeline diameter $(\mathrm{m})$

$d_{\text {out }}$ Outside pipeline diameter (m)

$D$ Diameter

$E \quad$ Young's Modulus (GPa)

\footnotetext{
*Address all correspondence to this author.
}

$E M I$ Electromagnetic interference

$F B G$ Fiber Bragg Grating

FLET Flow line end termination

FLMT Flow line mid termination

$L \quad$ Pipeline length (m)

$p_{e} \quad$ Photo elastic constant

$P_{\text {in }} \quad$ Internal pressure $(\mathrm{Pa})$

$P_{e x} \quad$ External pressure $(\mathrm{Pa})$

$T$ Temperature (K)

$\alpha_{\Lambda} \quad$ Thermal expansion coefficient $\left(\frac{\mu \varepsilon}{K}\right)$

$\alpha_{n} \quad$ Thermo-optic coefficient $\left(\frac{\mu \varepsilon}{K}\right)$

$\varepsilon$ Strain - ratio of deformation per original length $\left(\frac{\mathrm{m}}{\mathrm{m}}\right)$

$\lambda_{b} \quad$ Bragg wavelength (nm)

$\lambda_{0}$ Baseline wavelength

$\mu \varepsilon \quad \mu$-Strain $\left(10^{-6} \frac{m}{m}\right)$

$\mu \varepsilon_{F} \quad \mu$-Strain due to fiber optic temperature changes

$\mu \varepsilon_{M} \quad \mu$-Strain due to other mechanical forces

$\mu \varepsilon_{P} \quad \mu$-Strain due to external pressure

$\mu \varepsilon_{Q} \quad \mu$-Strain due to thermal expansion of pipeline 


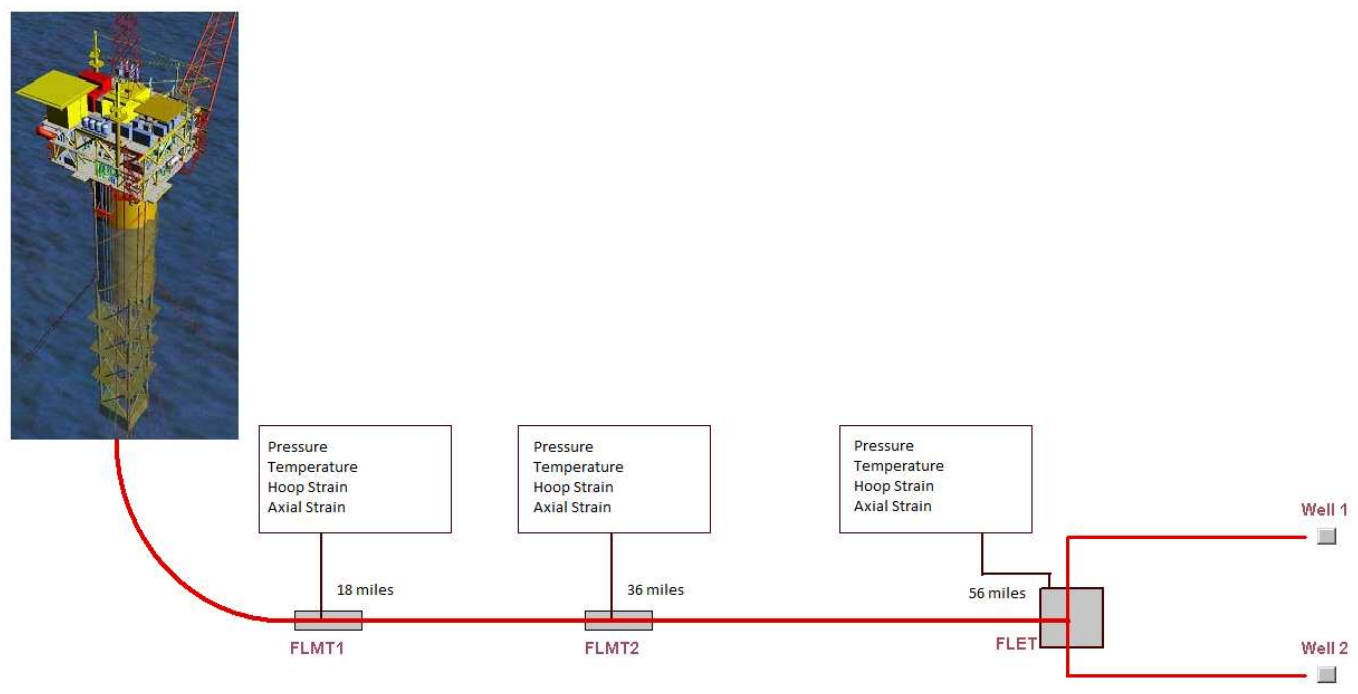

FIGURE 1. MONITORED MEASUREMENT STATIONS ALONG THE 90 KM (56 MILE) PIPELINE FROM WELL-HEAD TO SPAR.

\section{BASS LITE OVERVIEW}

Mariner Energy, Inc., now Apache Deepwater LLC, developed the primary production system for its Bass Lite deepwater field in the Gulf of Mexico. It is located in Atwater Valley Block 426. Bass Lite utilizes an 20.3-cm (8-inch) diameter, 90-km (56mile) long flow line that transports natural gas from the well head to Devils Tower located on Mississippi Canyon Block 773. The completed system allows production of up to 130 million cubic feet of natural gas per day (MMcf/d) from the two wells at Bass Lite, up from previous early production levels of 70-75 MMcf/d. Current daily production from the field is $118 \mathrm{MMcf} / \mathrm{d}$. Bass Lite water depth is approximately 2,050 m (6,750 feet), and production commenced operation in February 2008.

This report details the installation of the advanced instrumentation and resulting operational data from startup of the Bass Lite deepwater field in the Gulf of Mexico. To obtain the data, fiber optic sensors were used in this application for the longdistance signal transmission capability along a 90-km (56-mile) subsea tieback to the Devils Tower Spar. Fiber optic sensors are attractive in deepwater because of their multiplexing capability, immunity to electromagnetic interference, low vulnerability to water, and ruggedness. Topside software provides analysis of the optical signals and displays data at platform locations and onshore sites in realtime. As part of this project, a new web-based signal protocol was developed to increase the reliability of transmission over an intermittent connection with high latency. As the data is streamed to an onshore server location, remote viewing capability has allowed operators, technicians, and management to retrieve current and historical data. In addition to viewing streaming data, analysis is performed to verify pig passage, hydrate build-up, plug locations, and sensor validation.

\section{FLOW LINE INSTRUMENTATION METHODS}

This monitoring is accomplished with a variety of measurement devices that give axial, hoop, and reference pipeline strains at multiple sensor locations as shown in Figure 1. Temperature, pressure, axial strain and hoop strain values were measured within consolidated sensors stations at two flowline mid terminations (FLMT) and the flowline end termination (FLET) locations. $F L M T_{1}$ was located a distance of 18 miles from the Spar, $F L M T_{2}$ was at 36 miles and FLET measurements were taken near the wellhead at 56 miles from Devils Tower.

\section{Pre Installed Sensor Stations}

The first fiber optic sensing system deployed in subsea applications was performed on the Troika project in the Gulf of Mexico in 1997. Troika used FBG sensors with a very early and elementary signal conditioning unit. This early project was tasked to monitor the pressure without placing any penetrations into the 14 mile pipe-in-pipe subsea tieback. In addition to pressure; temperature and strain were monitored in real time. Since then other deployments utilizing fiber optic sensors were deployed on deepwater drilling risers and later on deepwater steel cantenary risers.

The application on Bass Lite as described in this paper, represents a significant advancement from these earlier projects and provides crucial engineering data on extremely long flowlines in deepwater fields. The sensors do not require penetrations into the flow stream, pressure vessel, or pipe wall. There were many new methods developed for Bass Lite and this paper describes three of the major features and first time technological advancements that were achieved. (1) A method was developed and implemented that sufficiently reduced light attenuation within the optical fiber 
sensor stations. This method allowed for a 112 mile round trip optical light signal. (2) This application along with past applications have very successfully used sensing systems that were installed prior to deployment in the subsea environment. This application added a new innovation that included a post installed sensor station. The post installation took place after the flowline had been deployed into deepwater. The final configuration, therefore, incorporated pre-installed sensor stations combined with post installed stations at water depths of approximately 7000 feet. And (3) real-time data transfer was achieved for sensors at extreme distance and water depth. Additionally, topside analysis and display algorithms were transferred in real-time to shore.

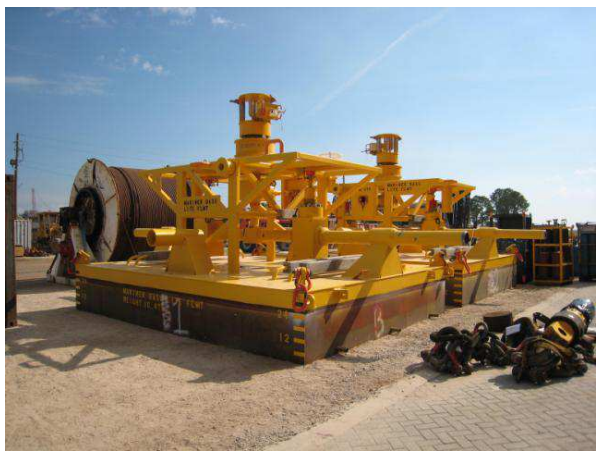

FIGURE 2. $\quad F L M T_{1}$ MEASUREMENT STATION.

The three sensor stations were integrated into the two $F L M T s$ and the FLET. Figure 2 is a photograph of $F L M T_{1}$ and is representative of $F L M T_{2}$ and $F L E T$. Figure 3 shows the sensor station as installed on the FLMT. Note that the sensors were added to these structures and were not a driver for the existence of the structures. The sensor station is coated with a semitransparent polyurethane. The white colored channels seen under the polyurethane layer are the fibers coated with the pressure balancing compound.

\section{Optical Signal Attenuation}

During the Bass Lite sensor station design stage, a critical concern was the amount of signal degradation that would result across the 56 mile long umbilical. Two separate twelve fiber optic strands were enclosed in 1/8 inch diameter stainless steel tubes. The fiber tube contained a gel saturated with a hydrogen scavenging substance. Its role was to absorb free hydrogen and lessen hydrogen intrusion into the silicon glass fibers. Over time hydrogen reaction with the fiber would increase its natural attenuation and possibly restrict future long distance data transfer . A low attenuation fiber typical of those used for long distance data transfer from the telecommunications industry was se-

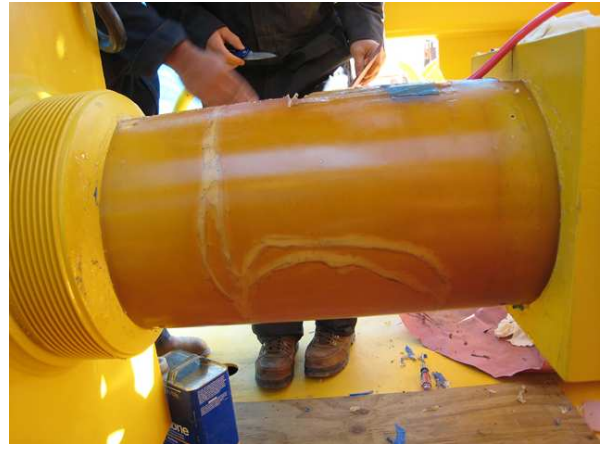

FIGURE 3. INSTALLATION ON THE MEASUREMENT STATION.

lected due to our low optical loss requirement. The twelve fiber stainless tubes were ruggedized by incorporating several spiral inconel wires and further encapsulated with a polyethylene extrusion giving a cable diameter of $5 / 8$ inch. The two cables were then integrated into the umbilical along with electrical cables and hydraulic lines. The twenty four fiber optic lines were shared between the sensor stations and the wellhead control and communications device.

In the region where the sensors were attached to the flow line, a high viscosity pressure balancing compound was extruded over and completely encapsulated the fiber optic strands. The introduction of this compound was necessary so that a uniform hydrostatic pressure would be applied to the fiber. This method provided a way to prevent non-uniform pressure induced deformation of the glass when placed into deepwater and the resultant application of high pressure. Additionally, micro bending of the fiber was eliminated in the region where external pressure could force the fiber to conform to irregularities in the pipeline surface features.

The natural attenuation of the fiber at 1550 nanometer wavelength was $0.177 \mathrm{~dB}$ loss per $\mathrm{km}$ fiber length. Since the tieback was 56 miles from the Spar, and data acquisition required round trip travel, fusion splices were used wherever possible due to their low optical loss (typical 0.01dB loss). Connectorization was required at four locations and each accounted for optical loss of 0.10 to $0.25 \mathrm{~dB}$ loss. The fiber optic sensor interrogator had input power of $50 \mathrm{~dB}$.

Figure 4 shows the strength of the FBG signal when interrogated at the 18 mile sensing location. Figure 5 indicates the signal strength at 36 miles and Figure 6 represents the signal strength at the sensors located near the welhead at a distance of 56 miles from the control room on Devils Tower. Each of the peaks represents individual FBG sensors that were designed to measure pressure, axial strain, hoop strain and temperature. Note the scale on the figures that denotes strength of reflected signal at each of the three locations. A very strong signal is obtained at 


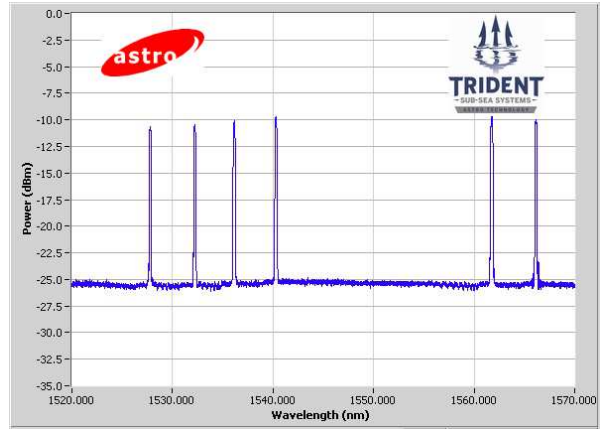

FIGURE 4. FBG SIGNAL STRENGTH AT 18 MILE SENSING LOCATION SHOWING 6 SENSORS.

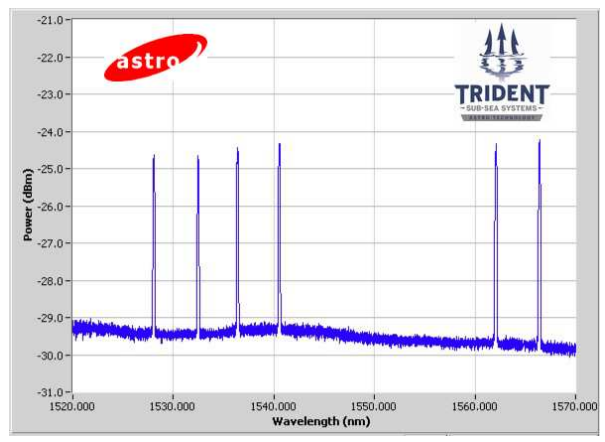

FIGURE 5. FBG SIGNAL STRENGTH AT 36 MILE SENSING LOCATION SHOWING 6 SENSORS.

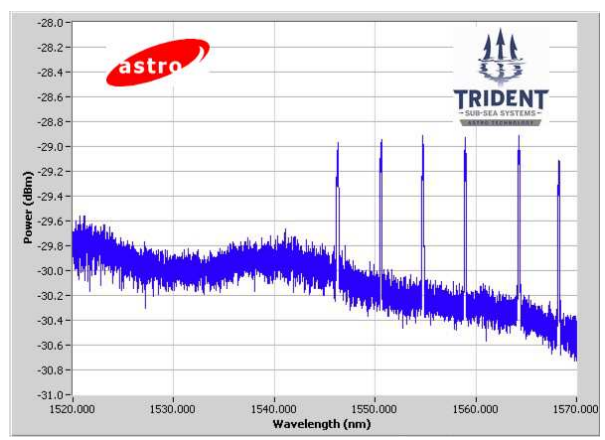

FIGURE 6. FBG SIGNAL STRENGTH AT 56 MILE SENSING LOCATION SHOWING 6 SENSORS.

the 18 mile station and with increased distance the signal strength decreases accordingly.

\section{Post Installed Sensor Stations}

During FLET installation into deepwater, the connector that interfaced the sensor station and fiber optic cable was dam- aged. Consequentially, a post installation method was developed. Hoop sensors, axial sensors, and temperature sensors were integrated into a thin stainless steel sheet that was molded onto an 8 inch diameter pipe segment. Pressure balancing compound was applied to the fiber strands and then overmolded with a 0.5 inch thick polyurethane coating. This post installed sensor station was then fitted with appropriate ROV compatible connectors and a clamping system.

This device was installed by use of an ROV and attached to the flowline at approximately 5 feet from the egress point of the FLET. Following installation, it was found that all sensor readings were operational. However, axial strain was difficult to obtain, due to less effective coupling between the FBGs and pipeline interface, relative to that of sensors bonded directly to the pipe used in pre installation methods. Hoop strain and subsequent pressure measurements were effectively measured along with temperature readings.

The post installed system represents a successful achievement, but additional work needs to be preformed to improve coupling between the sensor station and pipeline interface.

\section{Sensor and Data Calibration}

Following flowline installation into the Bass Lite field, calibration efforts were performed on all sensors while at water depth and under hydrostatic pressure. The flowline was allowed to fill with seawater and equilibrate to static pressure and strain. During this phase, several days of topside pressure was applied to the flowline interior at varying pressure levels and data was recorded. While this operation was in progress, reading of strain, pressure, and temperature were monitored by the FBGs and correlated to the topside measurements. This date and correlation analysis formed the baseline for future measurements.

\section{SOFTWARE AND DATA ANALYSIS}

The Upstream industry presents many opportunities for utilizing measurement technology to monitor the long term reliability of production systems [1]. In particular, deep-sea pipeline monitoring poses a challenge due to the remote environment, intermittent weather incidents, and gradual fatigue factors. There is a desire for improved monitoring of existing and new projects to give insight into the conditions that lead to failure. Analytical models utilize the data to monitor the operational integrity for flow assurance and riser integrity. The Advanced Process Monitoring (APMonitor) software [2] continuously analyzes the tie-back line to ensure flow assurance and operational integrity of the system.

By using an optimization framework, a mathematical model simulates the corresponding measured values to present detailed information about the production system dynamics. This optimization framework uses a receding horizon of process measure- 
ments to capture the changing process conditions. The Advanced Process Monitoring (APM) approach has been utilized in the Downstream and Chemicals industry for a number of years [3] [4] [1] and finds new application in monitoring of Upstream production systems [5]. APM attempts to optimally estimate the true state of the dynamic system, given a real-time stream of measurements and a model of the physical process.

When measurements are viewed individually, they offer some insight into the dynamics of the production platform. When integrated together with an analytical model, the combined set provides a holistic view for flow assurance. Pressure, temperature, and flex strains are updated at $10 \mathrm{~Hz}$ frequency. This sampling frequency is important in order to accomplish objectives related to flow assurance, hydrate buildup monitoring, plug detection, and well-head valve monitoring.

The measurements from the fiber optic line are updated at frequency that is optimized to allow a sufficiently strong source signal and capture the appropriate system dynamics. Measurements returned to the optical sensor as a range of magnitudes over a limited frequency. Individual measurements are characterized by peaks in the power spectrum. The peak location is identified and recorded for comparison to baseline values. Changes in strain at the fiber Bragg grating (FBG) and along the fiber optic line cause the frequency of the peak $\lambda_{b}$ to shift according to Equation 1.

$$
\frac{\lambda_{b}-\lambda_{0}}{\lambda_{b}}=\left(1-p_{e}\right)\left(\mu \varepsilon_{M}+\mu \varepsilon_{F}+\mu \varepsilon_{Q}+\mu \varepsilon_{P}\right)
$$

Equation 1 is the basis for the temperature, axial, hoop, and pressure measurements. Additional detail on the derivation of each of these is provided in the following sections.

\section{Temperature Measurement}

The temperature probe is a series of FBG on the fiber optic line that is not attached directly to the surface of the pipe. In this disconnected condition, only fluctuations in pressure and temperature affect the strain at the probe location. Pressure conditions are dictated by the depth of ocean and are relatively constant with the exception of tides and wave action above the sensor. Equation 2 is a rearrangement of Equation 1 without the term for other mechanical sources of strain $\left(\mu \varepsilon_{M}\right)$ or thermal expansion of the pipeline $\left(\mu \varepsilon_{Q}\right)$.

$$
\begin{aligned}
& \mu \varepsilon_{F}=\frac{\lambda_{b}-\lambda_{0}}{\lambda_{b}\left(1-p_{e}\right)}-\mu \varepsilon_{P} \\
& \mu \varepsilon_{F}=\left(\alpha_{\Lambda}+\alpha_{n}\right)\left(T-T_{0}\right)
\end{aligned}
$$

Deviation of temperature from the nominal value $T_{0}$ is related to $\mu \varepsilon_{T}$ by the coefficient of linear expansion $\left(\alpha_{\Lambda}\right)$ and the refraction index $\left(\alpha_{n}\right)$. Under the conditions that are encountered in this monitoring system, the value of $\alpha_{n}$ is much larger than $\alpha_{\Lambda}$. Further rearrangement of Equation 2 gives an explicit solution form for temperature $(T)$ from measured peak value $\left(\lambda_{b}\right)$ as shown in Equation 3.

$$
T=\frac{\frac{\lambda_{b}-\lambda_{0}}{\lambda_{b}\left(1-p_{e}\right)}-\mu \varepsilon_{P}}{\left(\alpha_{\Lambda}+\alpha_{n}\right)}+T_{0}
$$

\section{Axial Strain Measurement}

The axial strain sensor is attached in an axial direction to the surface of the pipe. Fluctuations in internal and external pressure, temperature, and pipeline vibration or movement affect the strain at the probe location. Axial strain is calculated after compensation for temperature induced strain. Equation 4 is a rearrangement of Equation 1 with the term for other mechanical sources of strain $\left(\mu \varepsilon_{M}\right)$ as the axial strain $\left(\mu \varepsilon_{\text {axial }}\right)$.

$$
\mu \varepsilon_{\text {axial }}=\frac{\lambda_{b}-\lambda_{0}}{\lambda_{b}\left(1-p_{e}\right)}-\mu \varepsilon_{P}-\mu \varepsilon_{T}-\mu \varepsilon_{Q}
$$

\section{Hoop Strain Measurement}

The hoop strain sensor is attached in the radial direction around the pipe. Fluctuations in internal pressure are best captured with the hoop strain gauges. Hoop strain is calculated after compensation for temperature induced strain. Equation 4 is a rearrangement of Equation 1 with the term for other mechanical sources of strain $\left(\mu \varepsilon_{M}\right)$ as the hoop strain $\left(\mu \varepsilon_{\text {hoop }}\right)$.

$$
\mu \varepsilon_{\text {hoop }}=\frac{\lambda_{b}-\lambda_{0}}{\lambda_{b}\left(1-p_{e}\right)}-\mu \varepsilon_{P}-\mu \varepsilon_{T}-\mu \varepsilon_{Q}
$$

\section{Pressure Measurement}

The pressure measurement is not a physical sensor but a combination of temperature and hoop strain measurements. The inside pressure $P_{i n}$ is calculated from a force balance on the pipe cross-section. The difference in pressures between the inside pressure $\left(P_{\text {in }}\right)$ and the external pressure $\left(P_{\text {out }}\right)$ will cause the pipe diameter to expand or contract from the unstrained condition. Elastic deformation of the pipe diameter is resisted by the carbon steel dictated by the Young's Modulus $(E)$. Equation 6 is an expression of this force balance.

$$
E=\frac{P_{\text {in }} \pi D_{\text {in }} L-P_{\text {out }} \pi D_{\text {out }} L}{\pi D_{\text {avg }} L \mu \varepsilon_{\text {hoop }}}
$$

Solving for $P_{\text {in }}$ gives the expression found in Equation 7.

$$
P_{\text {in }}=\frac{E \mu \varepsilon_{\text {hoop }} D_{\text {avg }}+P_{\text {ex }} D_{\text {out }}}{D_{\text {in }}}
$$




\section{Future Applications in Advanced Process Control}

As an extension to this project, Advanced Process Control (APC) is currently under investigation for platform gas processing, pipeline pressure, and pipeline temperature control [4]. APC uses detailed linear or nonlinear models to predict and optimize operations within process constraints [6]. In particular, with a 90 $\mathrm{km}$ (56 mile) sub-sea tieback line, there is significant flow, pressure, and heat transfer dynamics. Using a model-based approach, the dynamics are explicitly considered, leading to tighter control during startup, shut-downs, and throughput changes.

\section{FLOW ASSURANCE AND STRUCTURAL CHARACTER- IZATION}

Flow assurance and structural characterization is a key aspect of offshore, particularly deepwater developments. Tremendous progress during the past two decades in the understanding of the issues and the required technology has enabled the developments be designed and operated with low risk of flow assurance problems. However, the problems have not been eliminated due to system component failures or un-designed for operating conditions. Real time monitoring of the production and transportation system can help significantly reduce the occurrence and impact.

A series of fiber optic sensors for temperature, pressure, strain, and acoustic measurements have been developed, which form the basis of the methods used in pipelines, for determining the amount and location of paraffin deposition, for pig detection, and slug detection.

As one of the critical issues for deepwater oil and gas developments, flow assurance has progressed over the past two decades from mostly pipe sizing and flow pressure management to an integral part of the development and production process. Tremendous progresses have been made in the understanding of flow assurance issues and in the development of related technology. Operational procedures are commonly developed with flow assurance in mind. These progresses have enabled the deepwater development be designed and operated with low risk of flow assurance problems. Some subsea developments have been operated at almost no unplanned production shutdown.

However, the problems have not been eliminated due to system component failures or un-designed for operating conditions. Real time monitoring of the production and transportation system can help significantly reduce the occurrence and impact. The present paper discusses the use of non-intrusive fiber optic technology for this purpose.

Flow assurance is a cross-functional discipline with technical areas including multiphase flow and pressure management, thermal insulation, slugging issues, gas hydrates, paraffin deposition, asphaltene deposition, scales, erosion and internal corrosion, emulsion, etc.

\section{FIBER OPTIC SENSOR DESCRIPTION}

There are different configurations of fiber optic sensors. One of the most common is the fiber Bragg grating (FBG). The FBG is the type of sensor used to measure properties described throughout this paper, although other configurations could be similarly used. FBGs can detect and measure numerous physical quantities due to its high response to temperature and strain [7].

A FBG contains gratings etched on an optical fiber in a manner to create periodic changes in the index of refraction. The basic configuration is shown in Figure 7. The basic theory of FBG operation can be found in various publications. The FBG sensor depicted in Figure 7 consists of a single-mode optical fiber with gratings positioned at various locations along its length. The gratings are produced by doping the fiber with Germania and exposing it to an interference pattern of coherent light. Each grating is designed to reflect a certain frequency of light. Multiple such grating can be placed along a single fiber optic strand. The system is interrogated with a broadband light source and the multiple wavelength sensors within this source are detected.

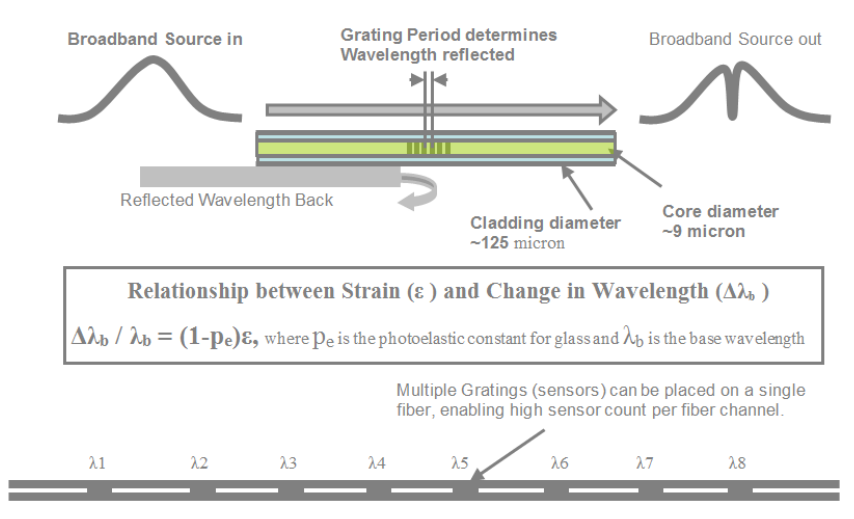

FIGURE 7. ILLUSTRATION OF A UNIFORM FIBER BRAGG GRATING WITH CONSTANT INDEX OF MODULATION AND PERIOD.

The FBG wavelength is sensitive to dimensional and temperature changes. The instrumentation senses the reflected frequencies and in turn determines the grating location and the dimensional change. Grating can be incorporated at any position along the fiber length. Changes in strain or temperature to which the optical fiber is subjected will consequently shift this Bragg wavelength, leading to a wavelength-encoded optical measurement. Table 1 details working ranges for typical FBG sensors.

One of the most important advantages of this sensor is the direct relation between the Bragg wavelength and the fiber strain, which makes absolute measurements of the strain possible. Under constant temperature conditions, the shift in the Bragg wave- 
TABLE 1. TYPICAL RANGES FOR FBG SENSORS.

\begin{tabular}{ll}
\hline Description & Typical Range \\
\hline Working wavelength range & $1520-1570 \mathrm{~nm}$ \\
Number of sensors along & \\
a single strand (FBG) & up to 32 \\
Resolution & $1 \mu \varepsilon$ \\
Accuracy & $5 \mu \varepsilon$ \\
Sampling Rate & up to $1 \mathrm{kHz}$ \\
Temperature range & -40 to $300 \mathrm{C}$ \\
\hline
\end{tabular}

length can be observed and related to strain by the relationship:

$$
\frac{\Delta \lambda_{b}}{\lambda_{b}}=\left(1-p_{e}\right) \varepsilon
$$

where

$\frac{\Delta \lambda_{b}}{\lambda_{b}}$ is the fractional shift in the Bragg wavelength

$p_{e}$ is the effective photoelastic constant

$\varepsilon$ is the longitudinal strain

The wavelength shift $\left(\Delta \lambda_{b}\right)$ for a temperature change of $\Delta T$ may be expressed as

$$
\Delta \lambda_{b}=\lambda_{b}\left(\alpha_{\Lambda}+\alpha_{n}\right) \Delta T
$$

where

$\alpha_{\Lambda}$ is the thermal expansion coefficient for the fiber

$\alpha_{n}$ represents the thermo-optic coefficient

Figure 8 shows a schematic of the typical response of a FBG when subjected to strain and resulting in a wavelength shift. By detecting this strain induced wavelength shift, a determination of absolute strain is made. Similarly, temperature induced shifts are detected resulting in absolute temperature.

Temperature compensation is provided by placing an additional FBG in the strain field area so that it is exposed to temperature but isolated from the strain field. The temperature induced shift is then subtracted from the strain measurement.

Since multiple FBG sensors can be incorporated into a single fiber optic strand, each provides a unique reflected signal as shown in Figure 9.

Fiber optic sensors have several distinct advantages over conventional sensing systems. Some of the major advantages are as follows:
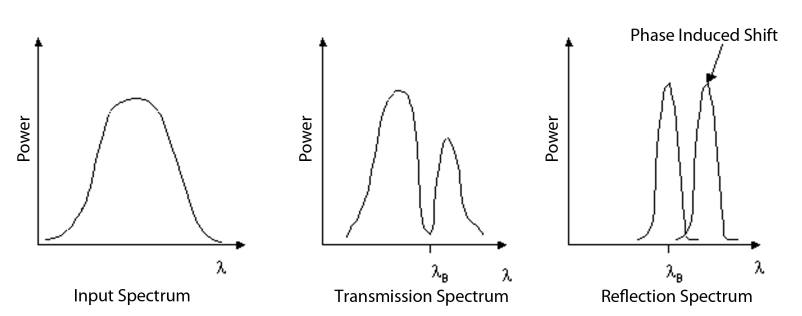

FIGURE 8. FUNCTIONAL PRINCIPLE OF A FIBER BRAGG GRATING.

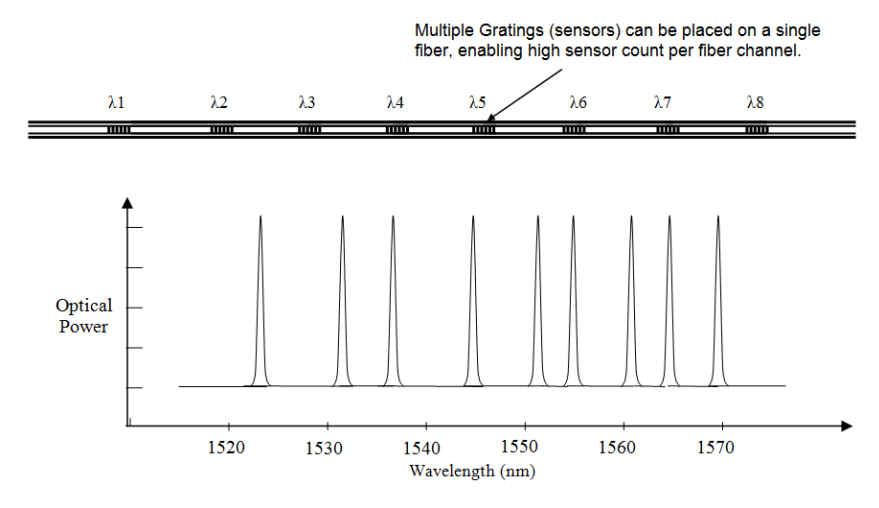

FIGURE 9. EXAMPLE OF MULTIPLE FBG SENSORS WITH UNIQUE REFLECTION CHARACTERISTICS.

Are safe to install and operate

Low vulnerability to water ingress and "shorting"

Non intrusive with no penetrations required into pressure vessel as per convection electronic sensors

No electric current required

Are immune to electromagnetic interference (EMI)

Sensors are easily multiplexed

Entire sensor system has little or no impact on the physical structure

Are multifunctional - can measure strain, temperature, pressure and vibration

Have long-life

Contain compact electronics and support hardware

Have high strain sensitivity

Can provide continuous real-time monitoring

Many of the advantages make FBGs a natural choice for applications in remote deepwater locations and extreme conditions.

\section{RECOMMENDATIONS}

Significant progress and technology advancement was achieved on the Bass Lite project. There were several additional 
advancements that should be pursued, primarily in the post installation area. Better coupling methods between sensors and pipeline should be pursued and a more streamlined and easy to install sensor station should be developed.

Following Bass Lite a Joint Industry Project (JIP) was founded to address these issues along with a multitude of other deepwater innovations. The Clear Gulf JIP relies on expertise provided by subject matter experts from the oil and gas industry in conjunction with technology experts from NASA. Much of the development work for Clear Gulf JIP is currently in progress at NASA facilities and at Astro Technology in Houston, Texas.

\section{CONCLUSIONS}

As deepwater fields in the Gulf of Mexico, West Africa, offshore Brazil, and elsewhere are developed it becomes increasingly important to detect crucial engineering properties of subsea equipment and environmentally induced conditions. Technology described in this paper provides actual operational information and data for improved design, flow assurance, and structural integrity.

The longest distance measurement to date were successfully achieved in the project involving the Bass Lite flowline. A new innovative post installed sensor station as been developed and intergrated into an advanced monitor system to accurately measure (in real-time) pressure, strain, and temperature.

These methods include a system that maximizes the optical power of the sensor interrogation unit. This was accomplished by reducing fiber attenuation by a multitude of techniques including incorporation of pressure balance compound, highly effective fusion spicing, low loss connectors, and elimination of sharp bends in the topside signal conditioning rack.

Software and data analysis methods utilized highly effective models via APMonitor. These results provide a system that utilizes the sensor measurements to capture changing process conditions and provides insight into flow assurance and structural integrity determination.

\section{REFERENCES}

[1] Spivey, B., Hedengren, J., and Edgar, T., 2010. "Constrained nonlinear estimation for industrial process fouling". Industrial \& Engineering Chemistry Research, 49(17), pp. 78247831.

[2] Hedengren, J., and Brower, D., 2012. "Advanced process monitoring of flow assurance with fiber optics". In AIChE Spring Meeting.

[3] Hedengren, J., Allsford, K., and Ramlal, J., 2007. "Moving horizon estimation and control for an industrial gas phase polymerization reactor". In Proceedings of the American Control Conference (ACC), pp. 1353-1358.
[4] Soderstrom, T., Zhang, Y., and Hedengren, J., 2010. "Advanced process control in Exxonmobil Chemical Company: Successes and challenges". In AIChE National Meeting.

[5] Hedengren, J., 2012. APMonitor Modeling Language. http://APMonitor.com.

[6] Findeisen, R., Allgöwer, F., and Biegler, L., 2007. Assessment and future directions of nonlinear model predictive control. Springer-Verlag, Berlin.

[7] Kersey, A., 2000. "Optical fiber sensors for permanent downwell monitoring applications in the oil and gas industry". IEICE Trans. Electron., E83-C(3), March, pp. 400404. 